\title{
Approaches To The Determination Of Strategy And Effect On Organizational Performance Of Standards Regulatory Bodies, A Case Study Of Kenya Bureau Of Standards (Kebs)
}

\author{
Vincent K. Cheruiyot
}

\begin{abstract}
Questions have always been posed about the performance of public organizations. These questions often emerge from crises in service provision or celebration of success. They do not provide the systematic evidence necessary to advance the science or practice of Public Administration. The absence of such evidence has arisen partly from lack of attention to the issue of performance in Public Agencies and from lack of relevant data. In recent years, more systematic information on the performance of Public Organizations has become available, and a literature on this topic is now emerging.

The results of empirical studies suggest that although environmental constraints are important, managers in Public Organizations have ample power to influence performance using a core managerial function in shaping strategy content, which can be defined as the patterns of service provision that are selected and implemented to form a central influence on Public-Service performance.

The Research paper will focus on approaches to determination of strategy and performance in Standards Regulatory Agencies with reference to Kenya Bureau of Standards (KEBS) which is a premier government agency for the provision of Standards, Metrology and Conformity Assessment (SMCA) services.
\end{abstract}

Key Words: Strategy, Strategic plan, Organizational performance, Performance evaluation

\subsection{The Kenya Bureau of Standards (KEBS)}

\section{Introduction}

The Kenya Bureau of Standards (KEBS) was established in 1974 and became fully operational by 1975. Its main activities at that time were development of standards and quality control for locally made products. The metrology laboratories started operating in 1980, followed by testing laboratories in 1982. Due to increased trade liberalization, import inspection commenced in 1995 and pre-verification of imports to conformity of standards was started in 2005.

The other services which KEBS now provides are training in Management Systems and Certification Services. KEBS also carries out other functions under the WTO Agreement on Technical Barriers to Trade (TBT) and the Agreement on Pre-shipment Inspection. Thus, over the last three decades, the scope of KEBS' activities has expanded from development of standards and provision of Standardization of commodities and codes of practice to cover Standardization and Conformity Assessment for commodities and services in all sectors of the economy not only in Kenya but also in the Eastern Africa region.

Administratively, KEBS is structured into four functional Divisions, in addition to the

Directorate namely:-

$\checkmark$ Standards Development and International Trade Division;

$\checkmark$ Metrology and Testing Division;

$\checkmark$ Quality Assurance and Inspection Division; and

$\checkmark$ Finance and Strategy Division.

$\checkmark$ Human Resource and Communication Division.

An analysis of KEBS' performance over the last plan period as well as interviews with members of the Council and staff has shown areas of weaknesses where improvements will need to be realized over the next plan period. The required improvements include the following: enhanced public awareness of KEBS and its products, development of a formal strategy for expanding scope of measurement fields, reducing testing turnaround time, review and harmonization of the pertinent Acts of Parliament, rationalization and implementation of the organization structure, analysis of staff workload and implementation of proper staffing levels, improving the ICT infrastructure, putting in place an effective Monitoring and Evaluation system and improving the overall governance structure. 


\subsection{Goals/Objectives}

For KEBS to achieve its strategic plan in line with the Kenya Government Vision 2030 it had to set up goals that would ensure it meets its vision of being a global leader in standards based solutions that deliver quality and confidence. Some of the goals that were set then include:

- To facilitate trade and the realization of the Kenya's social and economic priorities through standardization

- To provide national traceability of measurements to the International System of Units (SI)

- To provide national testing reference laboratory services

- Ensuring implementation of standards for fair trade and consumer protection.

- Reducing the level of substandard imports to promote fair trade

- Enhancing Quality Assurance and inspection capacity and competencies

- Ensuring KEBS organizational excellence through conformity and achieve recognition of its systems to international standards, guides and best practices

- To provide internationally recognized Certification Services

- To entrench a culture of quality in the Kenyan society

In addition to these goals, respective objectives and activities were aligned to divisions to improve resource allocation, implementation and accountability. A new organization structure that was to optimize delivery of the Bureau's goals and objectives was proposed. The 2007-2012 Strategic Plan was expected to cost about Kenya Shillings 8.9 billion(100 million US dollars) for which the necessary funds mobilization arrangements were specified in the Plan.

\subsection{Situation Analysis}

The KEBS operating environment and the Standardization, Quality assurance, Metrology \& Testing (SQMT) requirements in the world have greatly changed since 1974 when it was established. Locally the demand for its services has greatly expanded and, at the regional level the East African Community (EAC) SQMT Act and the EAC Metrology Bill require KEBS' participation. At the international level, the need for links to and networking with Standardization, Metrology and Conformity Assessment institutions in other countries and regions in the world has grown substantially.

Through an analysis of external environment, likely threats and opportunities were identified.

Appropriate remedial measures to address the threats have been included in the Plan whereas the opportunities will be exploited to enhance KEBS service delivery. In developing the 2007-2012

Plan the interests and concerns of stakeholders were also analyzed and taken into account when developing the goals, objectives and activities over the Plan period.

KEBS' ability to achieving its Plan objectives depended on the following key success factors, namely, effective information and knowledge management; capacity to attract and retain high calibre staff; dynamic and proactive leadership, customer orientation, and sufficient and well equipped laboratories.

\subsection{The Role of Standardization in an Economy}

The development and use of standards in an economy makes positive contribution to a nation by ensuring vital features such as quality, ecology, safety, reliability, efficiency compatibility, interchangeability and effectiveness; and thereby facilitating trade, spread of knowledge, sharing of technological advances and good management practices.

More specifically, Standards, Metrology and Conformity Assessment are important to an economy in a number of interdependent ways which include:-

> Metrology, through which measurements of ever-increasing accuracy, range and diversity are developed and maintained, provides a secure technical basis on which to anchor international agreements relating to trade and regulatory affairs. Secondly a metrology infrastructure in countries helps to remove technical barriers to trade and, thirdly it inculcates greater confidence in the measurement capabilities of individual countries. These contributions lead to increased international trade.

$>$ Standardization in products, processes and management systems leads to sustainable development and trade facilitation through the promotion of safety, quality, health and environmental protection. International standards also enable markets to operate effectively, increase competitiveness and provide opportunities for technology transfer and trade.

$>$ Conformity assessment plays a critical role in building confidence for sustainable development and trade by offering the assurance that a given product, process or management system meets the requirements that are specified in regulations and standards in a country. 
Development of quality systems is therefore an imperative for any country wishing to participate effectively in the increasingly globalised and liberalized international trade. Given the growing interest and concerns with Standardization in health, the environment, as well as the promotion of international trade, most countries continually enhance the capacity and capabilities of their quality infrastructure.

\subsection{Standardization in the Kenyan Economy}

As expounded above, an effective Standardization and quality assurance system is a vital pillar for the country's sustainable social and economic development. In Kenya, quality standards are increasingly being used by regulatory and other concerned agencies to ensure that the goods and services which are provided to users meet minimum quality, technical, safety and health requirements. At the same time a growing number of producers of goods and services in the country also use standards as a basis for ensuring that their products meet the requirements of their customers.

The Kenya Government recognizes the importance of quality standards and has shown commitment to their development as indicated in its major economic policy papers such as the ERS (economic recovery strategy), the Export Strategy Paper as well as the Kenya Vision 2030.

Secondly Kenya's economic growth is anchored on growth of exports of goods and services. The Envisaged dependence on export of goods and services to support economic development in

Kenya needs a strong quality infrastructure that will facilitate increased access and acceptability of Kenya's exports into the external markets. In this regard the Ministry of Trade and Industry

(MOTI), in its 2006-2011 Strategic Plan, underscored the role of Standardization by identifying the following as part of its core functions:-

$>$ Enhancing the development and promotion of quality standards for industrial products

$>$ Facilitating and promoting the Standardization and Conformity assessment activities

> Promoting fair trade practices and consumer protection

The importance of Standardization in Kenya is also reflected in the number of ministries and bodies that use standards in the provision of their services: They include the ministries of Trade and Industry; Health; Agriculture; Tourism, Education; Natural Resources; and devolution as well as institutions of higher learning such as Universities and other tertiary institutions. The importance of Standardization is bound to grow as the culture of quality gets embraced by government, producers and consumers.

The main providers of Standardization, Metrology and Conformity Assessment services locally are:-

$>$ KEBS for goods and services;

$>$ Kenya Plant Health and Inspectorate Services (KEPHIS) for plant materials;

$>$ Department of Veterinary Services for animal products and,

$>$ A growing number of private sector organizations for a variety of services.

As the leading organization that is responsible for Standardization, Quality Assurance, Measurement and Testing in the country, KEBS has a key role in the development and implementation of a national standardization policy and implementation program for sustainable socio-economic development.

\section{Strategy Content}

The concept of strategy content refers to how organizations actually behave, in contrast to strategies that are merely rhetorical or intended but unrealized. Through the 2007-2012 Plan KEBS was set to move from a vertically integrated system to increasingly autonomous institutions that are adequately equipped in terms of management practices, resources and facilities to provide pertinent services nationally, regionally, and at the international level. In that respect some core functional areas of KEBS became semi/fully autonomous agencies while others were reorganized for greater effectiveness. Where need arises, some of the business functions will be outsourced.

Boyne \& Walker (2004) present a model that conceptualizes strategy content in the public sector at two levels. First, strategic stance is the broad way in which an organization seeks to maintain or improve its performance. This level of strategy is relatively enduring and unlikely to change substantially in the short term (Zajac \& Shortell 1989). A broad range of management research supports this contention. For example, the literature on population ecology argues that structure and overall approach are set when an organization is established (Hannan \& Freeman 1977), and a range of evidence indicates that organizations are relatively inert.

Once routines are established, they are difficult to change (Amburgey, Kelly, \& Barnett 1993; Barnett \& Freeman 2001). The second level of strategy comprises the specific steps that an organization takes to operationalize its stance. These strategic actions are more likely to change in the short term (Fox-Wolfgramm, Boal, and Hunt 1998). Together, stance and actions constitute an organization's strategy content. The concept of strategy content refers to how organizations actually behave, in contrast to strategies that are merely rhetorical or intended but unrealized. 


\subsection{Strategic Action.}

The second dimension of strategy is based on five specific types of action that organizations may use to operationalize their stance. These actions concern changes in markets, services, revenues, the external organization, and the internal organization. The first three strategic actions reflect Porter's (1980) typology of strategy content. This typology has been extended to capture the constraints that public organizations may face in altering markets, services, or revenues. The strategic challenge for many public managers is to find better ways to deliver existing services in a fixed market with limited revenues. Thus, strategy may focus disproportionately on the organizational arrangements for service provision by altering external relationships or internal characteristics (Boyne \& Walker 2004).

Though the strategic actions of public agencies may be constrained because they cannot independently choose their own markets, they may be able to seek market entry or exit. A market can be defined geographically or through the characteristics of the users. Changes in markets occur when opportunities arise to provide existing services to new groups of citizens.

Conversely, a public agency can change its market by withdrawing from a particular geographical area or by no longer serving a specific group of users. Many examples exist of public organizations that have made such changes. For example, public agencies providing their current services to new users in different geographical areas( Osborne1 998), which might be achieved through takeovers or mergers (Walker \& Jeanes 2001).

Public organizations may also be constrained in the services they can provide (e.g., by legislation). Nevertheless, changes in needs or user expectations may lead public organizations to provide new services to existing users or to withdraw services. For example public housing land-lords' may diversify to social welfare services, through provision of multiple skills development and job services to the unemployed, and responses to user needs for services that cut across traditional service boundaries and client groups, such as community safety, public health, sustainability, and regeneration (Borins 1998, 2000; Enticott et al. 2002; Osborne 1998; Walker \& Jeanes 2001).

A major strategic task for public organizations is ensuring they have sufficient revenues to maintain or expand services. This type of strategic action might include raising extra income from fees, government grants, or charitable donations (Moon \& deLeon 2001; Moore 2000). In Stevens \& McGowan's (1983) study of 90 U.S. local governments identified four budget-expansion strategies available to public agencies: seek external revenue, increase internal revenue, seek additional state aid and authority, and allow the state to pay for highcost items. Strategic actions that focus on internal organization are extensive and widely documented in the literature. They cover variables such as structure, culture, processes, leadership, and a variety of metrics for improvement (Berry1994; Boyne \& Dahya 2002; deLancer, Julnes \& Holzer 2001; Douglas \& Judge, 2001; Westphal, Gulait, \& Shortell1 997). Strategies for external organization refer to the network or partnership through which many public agencies provide services (Provan \& Milward 1995).

Academics have devoted much attention to such arrangements, which include collaboration, consortia or joint ventures, and outsourcing services to private or nonprofit providers (B ardach1 998; Bevir and O'Brien 2001; Boyne 1998; Huxham 2000; Kickert, Klijn, and Koppenjan 1997; Lowndes \& Skelcher 1998; Meier \& O'Toole 2001; Provan \& Milward 2001; Wistow et al. 1992).

The five types of strategic action cover the three broad categories of behavior that are available to organizations: change the environment (move to a different market or shift the balance between existing markets), change the relationship with an existing environment (by altering services, revenues, or external structure), or change the organization itself (through modifications to internal structure.

\subsection{System Dynamics}

System dynamics is a perspective and set of conceptual tools that enable us to understand the structure and dynamics of complex systems. System dynamics is also a rigorous modeling method that enables organizations to build formal computer simulations of complex systems and use them to design more effective policies. Together, these tools allow them to create management flight simulators-micro worlds where space and time can be compressed and slowed so that organizations can experience the long-term side effects of decisions, speed learning, and develop our understanding of complex systems, and design structures and strategies for greater success (Sterman, 2000)

It uses the principles and techniques of controls systems to organizational and socio economic problems (Daalen et al, 2007). A system can be considered a control system if it has some common features. A control system senses the effect of external environment to the actual condition of the system compares the actual condition with the desired situation and then employs policies to determine what to do in given circumstances to reach the desired states. Control system also involves delays (there is always some time needed to feel the effect of the action) and information feedback (to know whether the desired condition achieved or not and what to do next). This is also why the control can be said to have a "dynamic" characteristic. 
In more practical term, the perception of system dynamics is that processes in the world are represented in terms of stocks (e.g. of material, energy, knowledge, people, money), flows between those stocks, and information that determines the values of the flows (Forrester 1958). Single events do not exist; events are abstracted to an aggregated view on feedback loops and delay structures.

System dynamic address some of the issues like what policies a firm should use as circumstance changes with time. Moreover, it can help organization design its information feedback structure to ensure that effective policies become possible.

If the system is significantly dynamic, i.e. if its state changes over time, it has causal and time dependencies, time-related constraints, etc., and is complex (so that it cannot be represented by analytical calculations, by formulas), the only way to explore the system behavior is to simulate its model - build a trajectory of the system in time. The model in this case is a set of rules telling how to obtain the next state of the system from the current state. Its essential idea is that the model takes a number of simulation steps along the time axis. At the end of each step, some system variables, which denote states of the system, are brought up to date for representing consequences ensued from previous simulation step. Initial conditions are needed to get the simulation to start the first time step.

At enterprise level of a multi-plant enterprise setup, a complex network of plants and their corporate head quarter gives rise to the emergence of a dynamic behavior due to the interdependence and feedback from the different plants. The interdependence may rise due to the direct influence of one plant decision in pursuing its local objective. This dynamic relation creates some feedback structures which needs to be address if the enterprise to investigate the implication for its decision making process.

At the plant level, the different operational functions at each plant which includes inventory management, production scheduling, and production operation are also another source of dynamic relationship. There is also a feedback structure between different decisions of the plant. For example, scheduling constrains the amount of production operation in a given day and production operation affects the raw material inventory management which in turn constrains the scheduling process. Hence, the performance of one function will have an implication for the performance of the other function thereby for the plant too.

An insight on the effect of these two levels of interaction on the operations of the enterprise can be obtained by using the system dynamic modeling which is well equipped to deal with such problems.

\section{Operational Performance}

The performance indicator of any operation management is used to help organizations define and evaluate how successful it is in terms of making progress towards its long-term organizational goals. These indicators can be specified by answering the question, "what is really important to different stakeholders?"

The three important objectives of performance of the operations management system are customer satisfaction, effectiveness and efficiency. The case of efficiency or productive utilization of resource is clear. For any kind of enterprises, the productive or optimal utilization of resource input is always a desired objective. However effectiveness has more dimensions to it which incorporates the fulfillment of multiple objectives with possible prioritization of objectives. This is not difficult to imagine since operations management activities involves different stake holders. This effectiveness has to be viewed in terms of the short and long time horizons because what may seem now an effective solution may not be all that effective in the future. In order to survive, the operations management system must not only be profitable and/or efficient but also satisfy customer also.

The effectiveness of the operations management system may depend not only on satisfying multiple objectives but on its flexibility or adaptability to change situations in the future so that it continues to fulfill the desired objective set while maintaining optimal efficiency.

The conflicting attributes of operations management to fulfill its predefined operational objective is important to take into consideration while defining its performance indicators. Ganeshan et al, (2001) put forward one alternative ways of seeing the most important factors in choosing the performance indicator of any enterprise. These can be put into three main categories: customer service metrics, asset metrics and time/speed/flexibility metrics.

The customer service measures how satisfied are both the internal and external customers of the enterprise. Asset metrics related with the capacity utilization. The most widely used performance indicator from the enterprise perspective includes delivery lead-time and inventory turns (the number of times that a company's inventory cycles or turns over per year) while traditional lean floor plant measures, such as cost per unit and manufacturing cycle time, are too shortsighted to address the interests of the different actors.

\subsection{Measurement Approaches of Organizational Performance.}

Intellectual capital is one of the measurements of organizational performance. The concept of intellectual capital was first proposed by John Kenneth Galbraith (1969), and many theories on intellectual capital have been proposed afterwards. However, due to the wide scope of intellectual capital, different scholars 
have different definitions, and no agreement has been reached. To effectively reflect corporate value, measurement of intellectual capital is important but is difficult. The following section will describe the most typical measure of the intellectual capital. Skandia avigator includes Skandia Navigator architecture, intellectual capital model, and market value framework. The Navigator is consisted of five components: financial, customer, process, human and renewal, and development focus. Roos et al. (1998) developed intellectual capital model using Skandia market value framework and described establishment of intellectual capital measure. Based on corporate operation concepts and strategies, key success factors should be found, and analysis of summary measures is conducted to find the specific measures for expression of intellectual capital. Edvinsson \& Malone (1997) suggested the Skandia market value framework and guidelines, and divided the intellectual capital into human capital,

Innovation capital, process capital, and customer capital,

\section{Methodology}

A variety of data collection approaches, such as survey, qualitative, or simulation approaches, should be encouraged. In light of the many interests determining the effects of strategies employed by many organizations to improve on their performance in a competitive and dynamics business environment, it is important that a better way be in place to support and measure the effectiveness of strategies employed herein.

It is also challenging to identify actions and responses in the complicated, fast-changing competition that characterizes many emerging economies (Chen, et al., 2010).

Moreover, since competition has both objective and subjective elements, a well-designed survey can capture the latter while probing into the "dynamic" and "relative" aspects of competitive dynamics as far as strategy adaptation is concerned.

Since, Competitive strategy, nonetheless, involves multilevel considerations; it is however beyond the scope of this research. This research therefore will employ the use of questionnaires to analyze the impact of strategies employed by KEBS a public company to achieve their desired performance. This method captures daily business operations and has merit when public competitive information is valid and accessible.

Finally, since most competitive strategy studies assume that one Firm responds because of an action taken by another Firm, it will be interesting to find out whether such moves are either an action or a counteraction. Besides, in business competition, an outsider may not be able to discern whether a price cut is in fact an attack, a defense, or a response to an outside event. Similarly, internal responses may be hard to observe and conceptualize, and thus remain unexplored in literature.

\subsection{Population and Sample}

The population of the study can be the employees of KEBS who should give testament to their performance as they have performed well in the last five years. All employees of this parastatal will be selected to form both the population and the sample of study. This will reduce the sample error of the study results.

Questionnaires will be developed with emphasis on questions that touch on all levels of operations whereby each employee will simply fill questions relating to their specific level. The objective will be to find out if there are strategies employed, how effective are they, can they be improved or are there other approaches and what are the problems faced in implementation and whether they are unique to an organization or common across the board.

\section{Conclusions}

Due to fast development of information technology and fierce competition, how to utilize information technology investment strategies for improving corporate operation performance and obtain competition advantages has become an important issue for companies and researchers. Apart from pursuing profits, the ultimate goal of companies is sustaining operation. However, the business environment is rapidly and complicatedly changing and global economy is in recession. Maintaining continuing operation is a challenge for operators. Thus Businesses must make definite strategies and input the limited resources in the core business to maintain a continuous operation and competitive advantages.

In the difficult environment, meticulous strategy planning, control and management are the key factors to maintain competitive power and continuing operation, especially information-intensive services. Information technology investment strategies can determine whether companies can surpass their rivals and obtain leading advantages. This should be the route adopted by KEBS.

Besides IT investment, allocation of complementary assets is the key to helping KEBS achieve higher operation performance and obtain competitive advantages. Better operation performance evaluation model can assist companies to conduct well performance management, understand driving factors of operation, precisely measure operation performance and guide it to develop and gain profits now and in the future. 


\section{Recommendations}

KEBS as a government agency is equally not exempt from evaluation of its performance. It has responsibilities to customers, companies, other governments by not only being able to generate revenue to the government but also provide and ensure quality of services and goods that are used in the country, the East Africa and the larger Africa as a whole. As such it need to come up with strategies, systems and performance benchmarks for evaluating its performance in light of competition from other quality assurance organizations.

In addition to this, KEBS must develop an integrated system(s) that will utilize the human/ intellectual capital with the other systems in use. It must therefore train and motivate its working force, develop new systems, do away with obsolete systems and be willing to source or subcontract services that don't form their core business.

Finally, KEBS must have an evaluation and monitoring system in place that will measure performance, will compare its performance to those of yester years, the best in the industry and the world. The evaluation system must consider both the qualitative and quantitative parameters in determining the performance of KEBS so as to give not only quality services and goods but quality information that will aid the various stakeholders to make informed decisions and therefore be satisfied in the process.

\section{References}

[1]. Boulding, W., Kalra, R. S. and Zeithaml, V. A. (1993). "A dynamic process model of service quality : from expectations to behavioral intentions," Journal of Marketing Research, 30, pp 7-27.

[2]. Bharadwaj, A., Bharadwaj, S. and Konsynski, B. R., (1999). "Information Technology Effects on Firm Performance as Measured by Torbin's q," Management Science, 45(6), pp.1008-1024.

[3]. Edvinsson, L., and Malone, M. S. (1997). Intellectual Capital - Realizing Your Company's True Value by Finding its Hidden Roots. New York Harper Business.

[4]. Hu, Q., and Plant, R.T. (2001) "An Empirical Study of the Causal Relationship between IT Investment and Firm Performance," Information Resource Management Journal, 14(3), pp 15-26.

[5]. The Kenya Bureau of Standards Strategic Plan for 2003/4 - 2006/7

[6]. The Kenya Bureau of Standards (Interim) Strategic Plan for the Period 2007- 2012

[7]. KEBS 30 year Business Plan

[8]. The Master Plan Study for Kenyan Industrial Development (MAPSKID) By Sanyu, Consultants INC and KRI Internal Corp for JICA and the Ministry of Trade and Industry, 2007

[9]. General Guidance and Direction for Negotiating the 2007/08 Performance Contracts; Office of the President Circular $\mathrm{OP} / \mathrm{CAB} / 13 / 1 / 1 \mathrm{~A}$ of 26 th April, 2007

[10]. Quarterly Performance Report - State Corporations; Ministry of Finance January 2005

[11]. Metrology, Standardization, and Conformity Assessment: Building an Infrastructure for Sustainable Development, ISO Central Secretariat, 2006

[12]. ISO and the Consumer; ISO Central Secretariat, 2005

[13]. The State Corporations Act, CAP 446, Revised Edition, 1987.

[14]. The State Corporations (Performance Contracting) Regulations, 2004

[15]. The Standards (Kenya Accreditation Service) Regulations, 2005

[16]. The Verification of Conformity to Kenya Standards of Imports Order, 2005, An Overview of Conformity Assessment in International Trade; ITC/ISO Bulletin No.72, December 2005 